\title{
Análise de coberturas com telhas de barro e alumínio, utilizadas em instalações animais para duas distintas alturas de pé-direito
}

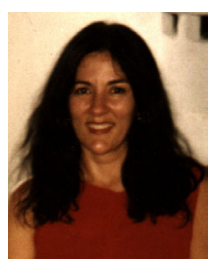

Rodrigo C. Santos ${ }^{1}$, Ilda de F. F. Tinôco ${ }^{2}$, Marcos O. de Paulo ${ }^{3}$, Marcelo B. Cordeiro ${ }^{4} \&$ Jadir N. da Silva ${ }^{5}$

\author{
1 DEA/UFV. Viçosa, MG. Fone: (31) 3899-1859, Fax: (31) 3899-2944. E-mail: rcouto@alunos.ufv.br \\ 2 DEA/UFV. Viçosa, MG. Fone: (31) 3899-1884, Fax: (31) 3899-2944, E-mail: iftinoco@mail.ufv.br (Foto) \\ ${ }^{3}$ Departamento de Engenharia Civil/UFV. Viçosa, MG. Fone: (31) 3891-5295. E-mail: eg39130@correio.ufv.br \\ 4 DEA/UFV. Viçosa, MG. Fone: (31) 3891-9439. E-mail: eg32272@correio.cpd.ufv.br \\ 5 DEA/UFV. Viçosa, MG. Fone: (31) 3899-2729. E-mail: jadir@mail.ufv.br
}

Protocolo 072 - 23/5/2001

\begin{abstract}
Resumo: Este trabalho teve como objetivo a análise de coberturas com telhas de barro e alumínio, comumente utilizadas em instalações animais, para duas distintas alturas de pé-direito, em condições de inverno no Brasil. O experimento foi realizado com modelos reduzidos de galpões avícolas, escala 1:10, e a análise foi feita quantificando-se a Carga Térmica de Radiação (CTR) e o Índice de Temperatura de Globo Negro e Umidade (ITGU) em diferentes horários, ao longo do período experimental. O experimento foi montado segundo um esquema de parcelas subdivididas, no delineamento em blocos casualizados. A interpretação estatística dos dados experimentais foi feita por meio da análise de variância e regressão. Para os fatores qualitativos (tipos de cobertura e pédireito) as médias foram comparadas utilizando-se o teste de Tukey e/ou F, adotando-se o nível de $5 \%$ de probabilidade; já para o fator quantitativo, os modelos foram escolhidos com base na significância dos coeficientes de regressão, utilizando-se o teste t em nível de $5 \%$ de probabilidade, o coeficiente de determinação e o fenômeno em estudo. Verificou-se, através deste experimento, que nas horas de frio mais intenso todas as coberturas causaram desconforto térmico e todos os protótipos tiveram UR acima do máximo tolerável para o conforto animal.
\end{abstract}

Palavras-chave: tipos de cobertura, ambiência animal, conforto térmico

\section{The analysis of ceramic tile and aluminum covers, used in animal facilities for two different foot-right heights}

\begin{abstract}
This research had as objective the analysis of ceramic tiles and aluminum roof, commonly used in animal facilities, for two different heights, under Brazilian Winter conditions. The experiment used reduced models of poultry houses (scale 1:10) and the analysis was made by the values of Thermal Load of Radiation (TLR) and of Black Globe and Humidity Index (BGHI), at different times along the experiment. The trial was conducted in randomized complete block design. The statistical interpretation of the experimental data was made through the variance and regression analysis. For the qualitative factors (roof types and height), the means were compared using the Tukey's and/or F test, at $5 \%$ level of probability. For the quantitative factors, the models were chosen based on the significance of the regression coefficients, applying the test, at $5 \%$ level of probability, the determination coefficient and the studied phenomena. It was verified through this experiment that during the hours of more intense cold, all the coverings caused thermal discomfort and all the prototypes had relative humidity above the tolerable maximum for the animal comfort.
\end{abstract}

Key words: covering types, animal environment, thermal comfort

\section{INTRODUÇÃO}

Com a globalização da economia mundial e conseqüente expansão das fronteiras mercadológicas, a competitividade tornou-se crescente e os produtores que se sobressaíram tiveram que aumentar sua produção e produtividade, para conseguirem atender à demanda de mercado, visto que num mundo onde a concorrência é grande, fatores ambientais, como a variação térmica, passam a ser de grande interesse durante o processo de produção animal, pois podem acabar refletindo na qualidade de seu produto final (Tinôco, 1998).

Uma forma de se influenciar o ambiente térmico das instalações é o acondicionamento térmico natural, com ênfase à variação da concepção arquitetônica e dos materiais de 
construção (Rivero, 1986). Dentre os materiais de construção utilizados nas instalações animais, merecem destaque os das coberturas, os quais constituem um dos principais responsáveis pelo conforto térmico ambiental, influenciando diretamente o balanço térmico no interior das instalações (Moraes, 1999).

A maioria das pesquisas relacionadas aos materiais de cobertura para as condições brasileiras, tem-se pautado mais no que se refere ao seu arrefecimento térmico, uma vez que o País apresenta verões muito quentes (Rosa, 1984); contudo, os materiais de cobertura utilizados nas instalações animais podem não ser simultaneamente eficientes para condições de verão e de inverno. Por exemplo, instalações para maternidade e creche de suínos e instalações para aves na sua fase inicial de crescimento, devem ser protegidas de temperaturas muito reduzidas ou mesmo de variações bruscas de temperatura interna, fato que se constitui num grande problema, principalmente durante o período noturno e em condições de inverno, podendo gerar grandes prejuízos financeiros, uma vez que um animal jovem estressado por frio dificilmente recomporá a uniformidade e o seu desempenho produtivo potencial ao longo de sua vida, o que reforça a importância de se atentar para a necessidade de mantê-lo sempre em condições de conforto térmico, tanto no verão quanto no inverno (Teixeira, 1996).

Ante o exposto, este trabalho teve como objetivo analisar as coberturas confeccionadas com telhas de barro e alumínio, com e sem forro, comumente utilizadas em instalações animais, para duas distintas alturas de pé-direito, em condições de inverno, em Viçosa, MG.

\section{MATERIAL E MÉTODOS}

Este experimento foi realizado nas dependências da Área de Construções Rurais e Ambiência do Departamento de Engenharia Agrícola da Universidade Federal de Viçosa, UFV, em Viçosa, MG, nos meses de agosto e início de setembro de 2000. O clima local, segundo classificação de Koppen, é Cwa, ou seja, quente temperado chuvoso, caracterizado por verões quentes e invernos secos.

\section{Caracterização dos protótipos}

Para a execução deste experimento foram construídos modelos reduzidos de galpões avícolas, geometricamente similares, na escala 1:10, determinada a partir da relação entre as dimensões reais e as reproduzidas na estação experimental.

Testaram-se oito modelos reduzidos de galpões avícolas, cujas estruturas foram confeccionadas em madeira, possuindo um módulo de seção transversal com comprimento de $1,0 \mathrm{~m}$ e suas faces leste e oeste com fechamento opaco. Suas dimensões foram $1,2 \mathrm{~m}$ de largura e beiral de $0,20 \mathrm{~m}$, sendo 4 protótipos com altura de pé-direito de $0,32 \mathrm{~m}$ (padrão médio usual) e 4 com pé-direito de $0,42 \mathrm{~m}$ (proposto para condições brasileiras). Os pisos interiores dos modelos foram forrados com cama de maravalha de madeira e as coberturas tiveram inclinação de $30^{\circ}$ para telhas de barro e $15^{\circ}$ para telhas de alumínio.

Os modelos foram montados em terreno plano, nivelado e gramado, livres de sombreamento, orientados no sentido lesteoeste e distanciados 4,0 $\mathrm{m}$ um do outro. $\mathrm{Na}$ área experimental constou um abrigo meteorológico para registro permanente das condições climáticas externas.

\section{Característica das coberturas utilizadas nos protótipos}

Testaram-se 4 modelos reduzidos de galpões para cada altura de pé-direito, sendo que um recebeu cobertura com telhas de barro, um com telhas de barro com forro, outro com telhas de alumínio e o último com telhas de alumínio com forro, seguindose as especificações dos fabricantes, totalizando oito protótipos.

\section{Instrumentos e medições}

As leituras foram feitas durante dez dias experimentais, a cada duas horas, a partir de zero hora, no período de $24 \mathrm{~h}$, enquanto para as medições de temperatura de bulbo seco (Tbs) e úmido ( $\mathrm{Tbu}$ ) foram instalados higrômetros posicionados na altura correspondente ao centro de gravidade das aves $(0,30 \mathrm{~m}$ em escala real).

Para obtenção dos valores de temperatura de globo negro (Tgn) utilizaram-se termômetros de globo negro, tendo como sensores termômetros de vidro com escala -90 a $110{ }^{\circ} \mathrm{C}$, instalados próximos aos higrômetros.

A velocidade do ar foi obtida através de um anemômetro digital de hélices, sendo que as leituras foram feitas próximo aos higrômetros, e perto do centro da área experimental foi instalado um abrigo meteorológico, pelo qual se mediu as temperaturas de bulbo seco, bulbo úmido e velocidade do ar. Nas proximidades do abrigo instalou-se um termômetro de globo negro.

\section{Índices de conforto térmico}

Os valores do índice de temperatura de globo negro e umidade (ITGU) foram calculados utilizando-se a equação proposta por Buffington et al. (1977):

$$
\text { ITGU }=\text { Tgn }+0,36 \text { Tpo }-330,08
$$

em que:

Tgn - temperatura de globo negro, $\mathrm{K}$

Tpo - temperatura do ponto de orvalho, $\mathrm{K}$

Os valores da carga térmica de radiação (CTR) foram obtidos utilizando-se a equação proposta por Esmay (1969):

$$
\mathrm{CTR}=\sigma(\mathrm{TRM})^{4}
$$

em que:

CTR - carga térmica radiante, $\mathrm{W} \mathrm{m} \mathrm{m}^{-2}$

$\sigma \quad$ - constante de Stefan-Boltzmann, $\left(5,67 \times 10^{-8} \mathrm{~W} \mathrm{~m}^{-2} \mathrm{~K}^{-4}\right)$

TRM- temperatura radiante média, $\mathrm{K}$

A temperatura radiante média (TRM) descrita por Bond \& Kelly (1995) pode ser expressa pela equação:

$$
\mathrm{TRM}=100 \sqrt[4]{2,51 \sqrt{\mathrm{v}}\left(\operatorname{Tgn}-\mathrm{t}_{\mathrm{bs}}\right)+(\operatorname{tgn} / 100)^{4}}
$$

em que:

$$
\mathrm{V} \text { - velocidade do ar, } \mathrm{m} \mathrm{s}^{-1}
$$

\section{RESULTADOS E DISCUSSÃO}

\section{Índices térmicos ambientais}

Índice de temperatura de globo negro e umidade (ITGU): Após o estudo da análise de variância, geraram-se equações de regressão, de forma a se ter uma estimativa do comportamento 
de cada tratamento em cada diferente altura de pé-direito, dentro dos horários de observação, constatando-se que o modelo que melhor representou o ITGU dos tratamentos foi o cúbico. A Tabela 1 apresenta as equações de regressão ajustadas do ITGU em função dos horários de observação, com seus respectivos coeficientes de determinação $\left(\mathrm{R}^{2}\right)$ para cada tratamento e pédireito.

A partir das equações de regressão, foram construídos os gráficos das Figuras 1 (A, B, C e D), responsáveis pela representação gráfica dessas equações, nas quais se pode visualizar o perfil do ITGU de cada tratamento, nos dois pés-direitos, ao longo das horas de observação. Com base nessas figuras é possível verificar-se que o ITGU mínimo para
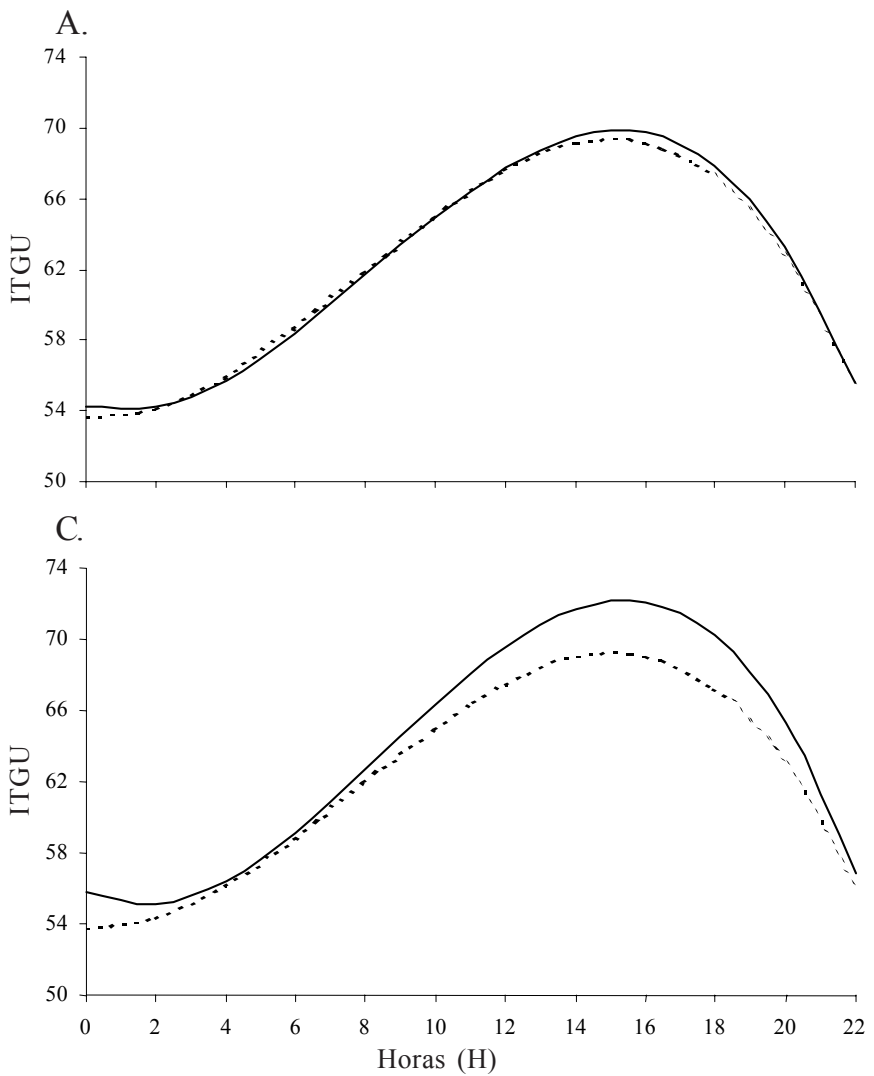

todos os tratamentos ocorreu entre uma e quatro horas, enquanto o máximo se deu entre 14 e $16 \mathrm{~h}$.

Observa-se, através dessas figuras, que os valores de ITGU para protótipos com pés-direitos maiores $(0,42 \mathrm{~m}$ na escala real) foram sempre inferiores àqueles encontrados nos protótipos com pés-direitos menores $(0,32 \mathrm{~m}$ na escala real) o que pode ser explicado principalmente pela maior proximidade entre os instrumentos e a cobertura e menor fração de céu frio no interior dos protótipos com pé-direito menor, e maior favorecimento à ventilação no protótipo com pé-direito maior. Assumindo-se que o limite mínimo de ITGU para que os frangos de corte não sofram de estresse por frio seja de 78,6, para pintos em sua primeira semana de vida, de 67,4 para pintos em sua segunda

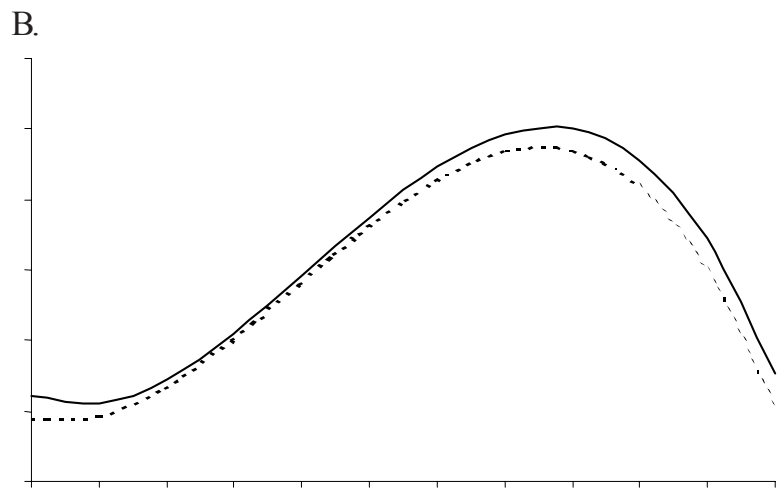

D.

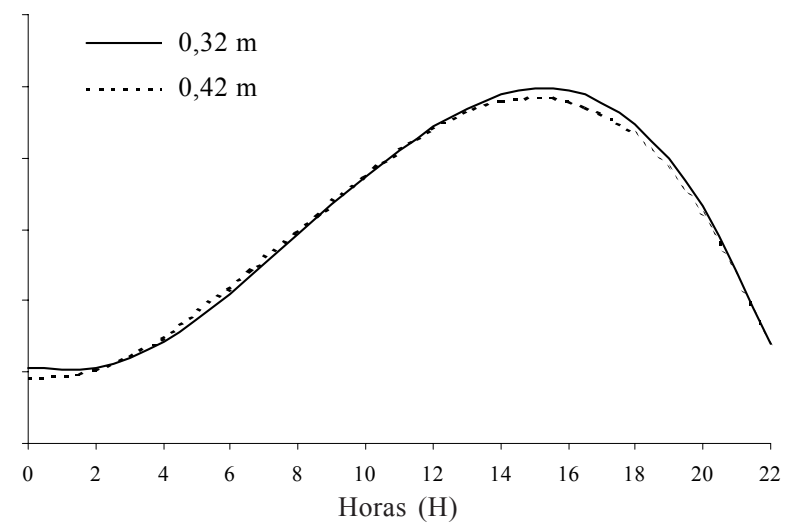

Figura 1. Estimativa do índice de temperatura globo negro e umidade (ITGU) para os tratamentos com telhas de barro (A), barro com forro (B), alumínio testemunha (C) e alumínio com forro (D) com duas alturas de pés-direito $(0,32$ e $0,42 \mathrm{~m})$ em função das horas

Tabela 1. Equações ajustadas de índice de temperatura de globo negro e umidade (ITGU) em função das horas (H) para os respectivos tratamentos e pés-direitos (P.D) e os coeficientes de determinação $\left(\mathrm{R}^{2}\right)$

\begin{tabular}{|c|c|c|c|}
\hline Tratamento ${ }^{1}$ & P.D. - m & Equações Ajustadas & $\mathrm{R}^{2}$ \\
\hline B & 0,32 & $\hat{\mathrm{Y}}=55,41780,9222 * * \mathrm{H}+0,3320 * * \mathrm{H}^{2} \quad 0,0131 * * \mathrm{H}^{3}$ & 0,762 \\
\hline B & 0,42 & $\hat{\mathrm{Y}}=53,94180,3752 * * \mathrm{H}+0,2515^{*} * \mathrm{H}^{2} \quad 0,0105^{* *} \mathrm{H}^{3}$ & 0,711 \\
\hline $\mathrm{Bf}$ & 0,32 & $\hat{\mathrm{Y}}=54,82340,7331 * * \mathrm{H}+0,2902 * * \mathrm{H}^{2} \quad 0,0116 * * \mathrm{H}^{3}$ & 0,743 \\
\hline $\mathrm{Bf}$ & 0,42 & $\hat{\mathrm{Y}}=53,59650,4358 * * \mathrm{H}+0,2616^{*} * \mathrm{H}^{2} \quad 0,0109 * * \mathrm{H}^{3}$ & 0,727 \\
\hline A & 0,32 & $\hat{\mathrm{Y}}=55,83350,9766^{* *} \mathrm{H}+0,3332 * * \mathrm{H}^{2} \quad 0,0130 * * \mathrm{H}^{3}$ & 0,751 \\
\hline A & 0,42 & $\hat{\mathrm{Y}}=53,82660,1622 * * \mathrm{H}+0,2249 * * \mathrm{H}^{2} \quad 0,0097 * * \mathrm{H}^{3}$ & 0,677 \\
\hline Af & 0,32 & $\hat{\mathrm{Y}}=54,28140,5502 * * \mathrm{H}+0,2736 * * \mathrm{H}^{2} \quad 0,0112 * * \mathrm{H}^{3}$ & 0,750 \\
\hline Af & 0,42 & $\hat{\mathrm{Y}}=53,71690,2445^{* *} \mathrm{H}+0,2392 * * \mathrm{H}^{2} \quad 0,0102 * * \mathrm{H}^{3}$ & 0,704 \\
\hline
\end{tabular}


semana de vida e de 65,0 para aves entre a terceira e a sexta semana de vida, valores estes propostos por Teixeira (1996) entende-se que, para condições de frio, pés-direitos mais baixos são os mais adequados ao conforto térmico de animais de pequeno porte.

No caso das coberturas com telha de alumínio com forro, a diferença entre o ITGU do tratamento com pé-direito, de 0,32 e 0,42 m, foi mínima, o que ocorreu, provavelmente, pelo fato da quantidade de calor proveniente das telhas para $o$ interior dos protótipos ser muito elevada, minimizando a influência da exposição ao céu frio, mantendo assim próximos os valores de ITGU para ambos os tratamentos, independente do pé-direito.

Ao se comparar os dados das Figuras 1A e 1B, representativas das coberturas de barro testemunha e barro com forro, respectivamente, observa-se que, ao se adicionar forro à cobertura com telhas de barro, ocorreu uma redução geral nos valores de ITGU, além de uma aproximação entre as curvas dos valores de ITGU dos tratamentos com pés-direitos de 0,32 e $0,42 \mathrm{~m}$, principalmente nas horas mais quentes do dia. Infere-se, daí, que a utilização de forro confere maior inércia térmica ao conjunto, o que é desejável para o inverno.

A Figura $1 \mathrm{C}$ mostra que, para tratamentos com cobertura de telha de alumínio testemunha, a elevação do pé-direito, de 0,32 para $0,42 \mathrm{~m}$, acarretou variação de ITGU maior que a encontrada no tratamento com telhas de alumínio com forro. Comparando-se os dados das Figuras $1 \mathrm{C}$ e $1 \mathrm{D}$, verifica-se que a utilização de forro associado às telhas de alumínio, proporcionou maior inércia térmica à cobertura e redução geral nos valores de ITGU, fato este também verificado nos tratamentos com telha de barro com forro.

Carga térmica de radiação (CTR): Assim como para o ITGU e de acordo com a análise de variância, geraram-se equações de regressão de forma a se ter uma estimativa do comportamento de cada tratamento em cada diferente altura de pé-direito, nos horários de observação, sendo que o modelo que melhor representou a CTR dos tratamentos foi o cúbico-raiz. A Tabela 2 apresenta as equações de regressão ajustadas da CTR em função dos horários de observação, com seus respectivos coeficientes de determinação $\left(\mathrm{R}^{2}\right)$ para cada tratamento e pé-direito.

A partir das equações de regressão da Tabela 2, foram construídos os gráficos apresentados nas Figura 2 (A, B, C e D), responsáveis pela representação gráfica dessas equações, nas quais se pode visualizar o perfil da CTR de cada tratamento, nos dois pés-direitos, ao longo das horas de observação. Com base nessas figuras, é possível verificar-se que a CTR mínima para todos os tratamentos ocorreu entre 1 e $4 \mathrm{~h}$, enquanto a máxima se deu entre 12 e $14 \mathrm{~h}$.

A Figura 2A mostra que os valores de CTR, em $\mathrm{W} \mathrm{m}^{-2}$, dos tratamentos com telha de barro, para protótipos com pés-direitos maiores $(0,42 \mathrm{~m}$ na escala real) foram inferiores àqueles encontrados nos protótipos com pés-direitos menores $(0,32 \mathrm{~m}$ na escala real) o que pode ser explicado, assim como para o ITGU, pela maior proximidade entre os instrumentos e a cobertura e menor fração de céu frio no interior do protótipo com pédireito menor e maior favorecimento à ventilação no protótipo com pé-direito maior.

Ao se comparar as Figuras 2A e 2B, representativas, das coberturas de barro testemunha e barro com forro, respectivamente, observa-se, ao se adicionar forro à cobertura com telha de barro, redução geral nos valores de CTR e um distanciamento entre as curvas de CTR dos tratamentos com pés-direitos de 0,32 e 0,42 $\mathrm{m}$, principalmente nas horas mais frias do dia. Infere-se, daí, com base na análise da CTR, que a utilização de forro confere maior inércia térmica ao conjunto, ao mesmo tempo em que diminui a variação de CTR entre as duas curvas durante o período de medição.

A Figura 2C mostra que para tratamentos com cobertura de telhas de alumínio, a elevação do pé-direito, de 0,32 para $0,42 \mathrm{~m}$, causou diminuição da CTR, o que se explica pela variação da quantidade de céu frio sob a cobertura e aumento da ventilação sob a mesma.

A Figura 2D mostra que a utilização de forro não ocasionou variação expressiva nos valores de CTR, variando o pé-direito. Este resultado foge ao esperado, pois não evidencia a influência da ventilação e nem a exposição ao céu frio.

Tabela 2. Equações ajustadas de carga térmica de radiação (CTR) em função das horas (H) para os respectivos tratamentos e pésdireitos (P.D.) e os coeficientes de determinação $\left(\mathrm{R}^{2}\right)$

\begin{tabular}{|c|c|c|c|}
\hline Tratamento $^{1}$ & P.D. - $\mathrm{m}$ & Equação Ajustada & $\mathrm{R}^{2}$ \\
\hline B & 0,42 & $\hat{\mathrm{Y}}=373,662072,5076^{*} * \mathrm{H}^{1 / 2}+51,5072^{*} * \mathrm{H} 7,6332 * * \mathrm{H}^{3 / 2}$ & 0,645 \\
\hline $\mathrm{Bf}$ & 0,32 & $\hat{\mathrm{Y}}=382,056079,5917^{*} * \mathrm{H}^{1 / 2}+54,1714 * * \mathrm{H} 7,8893^{*} * \mathrm{H}^{3 / 2}$ & 0,729 \\
\hline $\mathrm{Bf}$ & 0,42 & $\hat{\mathrm{Y}}=368,298078,6243^{* *} \mathrm{H}^{1 / 2}+54,3628^{* *} \mathrm{H} 8,0130^{*} * \mathrm{H}^{3 / 2}$ & 0,696 \\
\hline Af & 0,32 & $\hat{\mathrm{Y}}=376,588079,9816^{* *} \mathrm{H}^{1 / 2}+54,9584 * * \mathrm{H} 8,0579 * * \mathrm{H}^{3 / 2}$ & 0,704 \\
\hline Af & 0,42 & $\hat{\mathrm{Y}}=377,213075,8965^{* *} \mathrm{H}^{1 / 2}+52,7764^{*} * \mathrm{H} 7,7706^{* *} \mathrm{H}^{3 / 2}$ & 0,692 \\
\hline
\end{tabular}



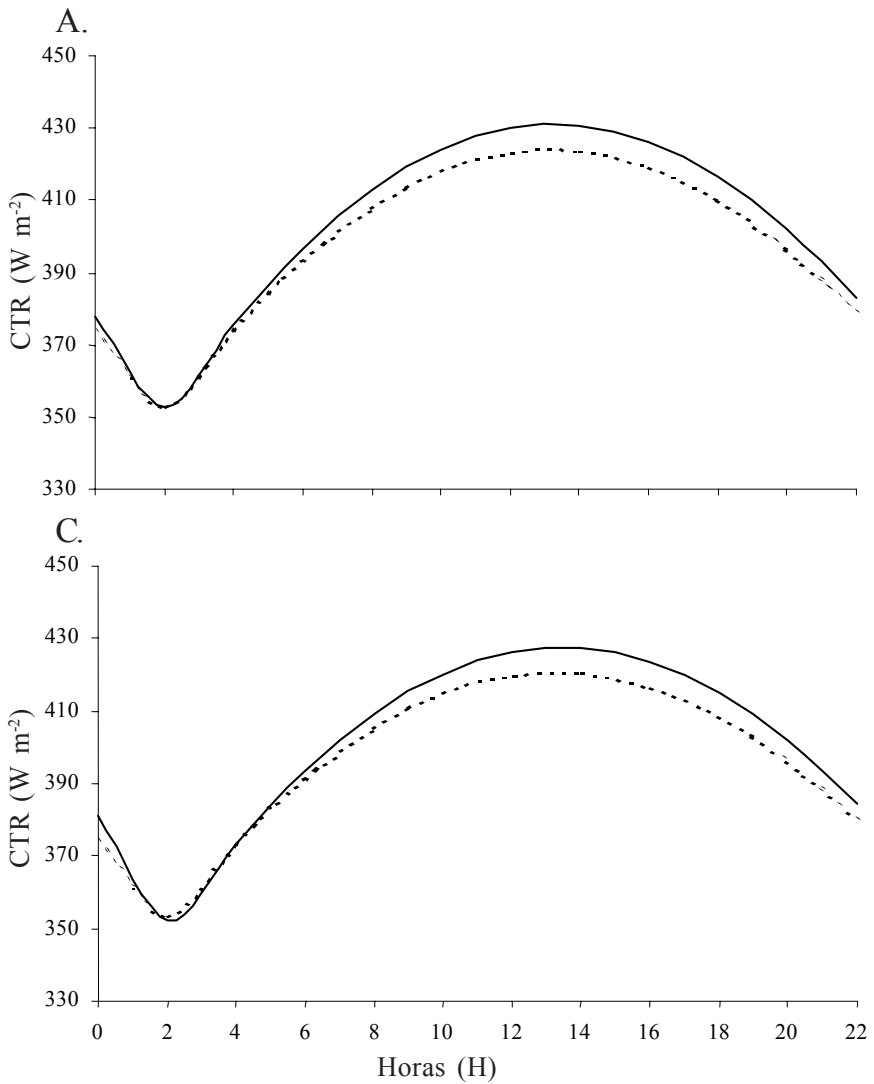

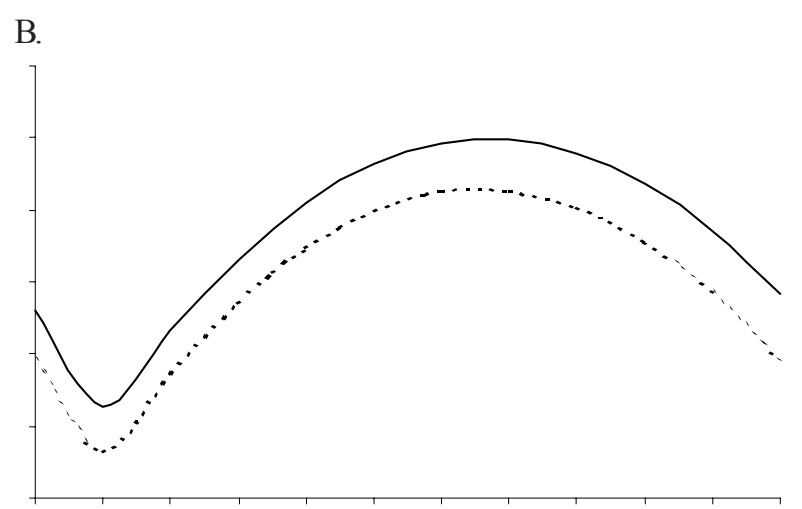

D.

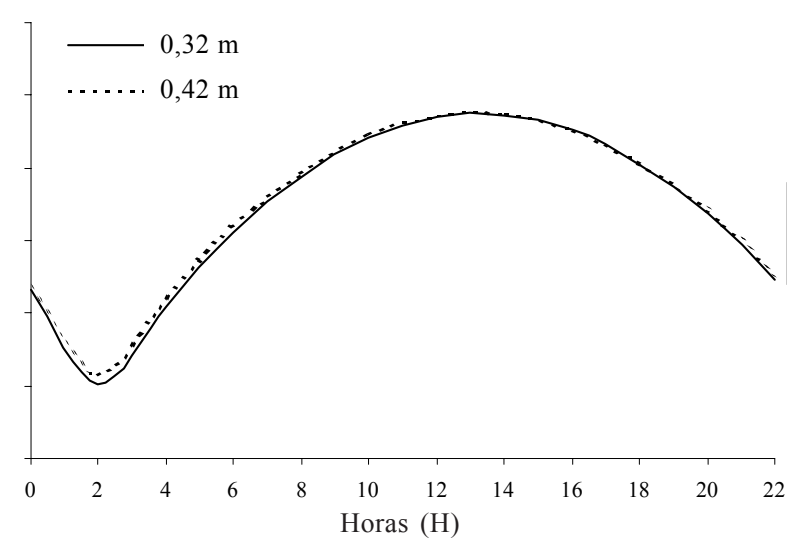

Figura 2. Estimativa da carga térmica de radiação (CTR) em W m², para os tratamentos com telhas barro (A), barro com forro (B), alumínio testemunha (C) e alumínio com forro (D), com duas alturas de pés-direitos (0,32 e 0,42 m), em função das horas

\section{CONCLUSÕES}

1. Quanto aos valores de ITGU e CTR, a utilização de forro junto às telhas de barro e alumínio, conferiu maior inércia térmica aos conjuntos, o que é desejável durante o inverno

2. A utilização de galpões com pé-direito de $0,32 \mathrm{~m}$ ( $3,2 \mathrm{~m}$ em escala real), propiciou valores de ITGU e CTR maiores que os encontrados em galpões com pé-direito de $0,42 \mathrm{~m} \mathrm{(4,2} \mathrm{m} \mathrm{em}$ escala real) nas horas de extremos térmicos, desejável para o inverno

3. Nas horas de frio mais intenso, todas as coberturas tiveram seus valores de ITGU abaixo do limite mínimo da zona de conforto térmico animal, sugerindo melhor isolamento das instalações durante este período.

\section{LITERATURA CITADA}

Bond, T.E.; Kelly, C.F. The globe thermometer in agricultural research. Transactions ASAE, St. Joseph, v.35, n.7, p.251-255, 1995.
Buffington, C.S.; Collazo-Arocho, A., Canton, G.H. Black globe humidity comfort index for dairy cows. American Society Agricultural Engineers, St. Joseph, 1977. 19p. Paper 77- 4517

Esmay, M.L. Principles of animal environment. 2. ed. Westport: CT Abi, 1969.325p.

Moraes, S.R.P. Conforto térmico em modelos reduzidos de galpões avícolas, para diferentes coberturas, durante o verão. Viçosa: UFV, 1999. 73p. Dissertação Mestrado

Rivero, R. Arquitetura e clima: condicionamento térmico natural. 2. ed. Porto Alegre: D.C. Luzzatto, 1986. 240p.

Rosa, Y.B.C.J. Influência de três materiais de cobertura no índice de conforto térmico, em condições de verão, para Viçosa, MG. Viçosa: UFV, 1984. 77p. Dissertação Mestrado

Teixeira, V.H. Resfriamento adiabático evaporativo na edificação de maternidade para suínos. Botucatu: UNESP, 1996. 93p. Tese Doutorado

Tinôco, I.F.F. Ambiência e instalações para avicultura industrial. In: Congresso Brasileiro de Engenharia Agrícola, 27, e Encontro Nacional de Técnicos, Pesquisadores e Educadores de Construções Rurais, 3, 1998, Poços de Caldas, MG. Anais...Lavras: UFLA/SBEA, 1998. p.1-86. 